\title{
Ameliorating effects of Cuscuta chinensis Lamak extract on hind-limb ischemia, and angiogenic- or inflammatory associated factors in ovariectomized mice
}

\author{
HYE JIN KIM* , HYUN YANG* ${ }^{*}$, DONG HO JUNG, JOO TAE HWANG and BYOUNG-SEOB KO \\ Korean Medicine Convergence Research Division, Korea Institute of Oriental Medicine, \\ Daejeon 34054, Republic of Korea
}

Received July 2, 2018; Accepted February 15, 2019

DOI: $10.3892 / \mathrm{mmr} .2019 .9977$

\begin{abstract}
Cuscuta chinensis Lamak (CCL) has traditionally been used in Korea to treat sexual disorders and skin problems. The aim of the present study was to investigate the effects of CCL extract on surgical injury-induced ischemia in the hind limbs of mice. Specifically, female C57BL/6 mice were ovariectomized, and their hind-limb vessels were ligated with surgical silk (6-0) and excised. CCL (150 or $450 \mathrm{mg} / \mathrm{kg} / \mathrm{BW}$ ) was then administered to the mice for 3 weeks, and the blood flow rate was evaluated using a laser Doppler system at $-7,0,7,14$ and 21 days following hind-limb ischemia. The serum expression profiles of angiogenic and inflammatory mediators were measured using an antibody array, and the transcript levels were reverse transcription-quantitative polymerase chain reaction. The rate of hind limb blood flow was normalized to non-ischemic lesions and revealed to be markedly elevated at 14 and 21 days following ischemia when compared with the vehicle group. The density of capillaries in the hind limbs was also significantly increased following treatment with CCL in a dose-dependent manner. In addition, the transcriptional expression of angiogenetic factors were upregulated, whereas that of inflammatory cytokines were downregulated. Finally, vascular endothelial cell migration and tube formation were evaluated in vitro using human umbilical vein endothelial cells (HUVECs) and identified to be significantly increased following treatment with CCL. Overall, the results of the present study indicate that CCL extract exhibits therapeutic potential for the treatment of hind-limb ischemia as it promotes peripheral angiogenic and anti-inflammatory effects in mice.
\end{abstract}

Correspondence to: Dr Byoung-Seob Ko, Korean Medicine Convergence Research Division, Korea Institute of Oriental Medicine, 1672 Yuseong-daero, Yuseong-gu, Daejeon 34054, Republic of Korea E-mail: bsko@kiom.re.kr

*Contributed equally

Key words: Cuscuta chinensis Lamak, hind-limb ischemia, blood flow perfusion, angiogenesis, inflammation

\section{Introduction}

Semen Cuscutae is the seed of Cuscuta chinensis Lam. (CCL, Cuscuta japonica Choisy), a parasitic plant of the Convolvulaceae family that must germinate close to its host plant (1). And CCL contains 6 active candidate compounds. The candidate active compound are rutin, hyperoside, astragalin, quercetin, kaempferol and isorhamnetin. The activity and amount of each of these compounds are being analyzed in another study. Thus we are unable to provide information regarding these clearly yet. The mature seed of CCL is harvested in the late fall and dried for use in alternative medicine in Korea. CCL has been extensively used to improve hepatic and renal functions, fatigue, high blood pressure, and chronic diarrhea (1-3). Ancient documents such as the Donguibogam, that describes principles and practices of eastern medicine, state that CCL improves vitality, as well as reduces back and knee pain, and regulates diabetes and sexual dysfunction when consumed frequently.

In post-menopausal women, hormone replacement therapy (HRT) with estradiol is the most effective remedy for multi-symptoms of the menopause syndrome; however, it is associated with several side effects including uterine bleeding, hyperplasia, and the risk of breast cancer (4). Previous studies have recommended that post-menopausal women with non-hysterectomy should take the lowest effective dose of HRT for the shortest amount of time possible to reduce the associated risks. Phytoestrogens, natural herbal compounds that structurally resemble estrogens and their metabolites, represent an alternative to synthetic estrogen and/or progesterone therapy (4). The consumption of phytoestrogens has been shown to improve menopausal symptoms such as hot flashes and night sweats in women (4).

Menopause is associated with an increase in low-density lipoprotein cholesterol concentration and subsequent defects of circulation such as sluggish blood flow, and varicose and spider veins (5). Moreover, peripheral vascular disease may occur in response to changes in serum lipid levels, shown to accelerate with age in menopausal women $(5,6)$. Moreover, estrogens can indirectly and/or directly affect vascular dysfunctions during the mediation of lipid profiles, as well as recovery from the ischemic damage leading to atherosclerosis and embolus in 
limbs (6,7). Regarding vascular functions, estrogens may also regulate inflammatory responses and apoptosis under ischemic stress (8).

Neovascularization occurs during pathological conditions such as ischemic, immune, and inflammatory responses, and seems to be driven by diverse cellular and molecular responses (9). The process of neovascularization includes vasculogenesis, angiogenesis, and arteriogenesis, all of which contribute to the repair and remodeling of damaged tissues during ischemia-related disease (9). Ischemic tissue conditions also regulate the expression of $\mathrm{C}-\mathrm{X}-\mathrm{C}$ motif chemokines (CXC) such as CXCL-8, CXCL-9, CXCL-10 and CXCL-12, as well as the interaction between these chemokines (CXCLs) and their receptors, CXCRs, in angiogenesis (10). Conversely, intracellular relations are mediated by endothelial cell adhesion molecules including CD31, CD45, CD54 and CD106. Ischemic stress also enhances the synthesis of pro-inflammatory cytokines such as TNF- $\alpha$, IL-6, and IL-1b in the muscle (9). Platelet activation also takes place under ischemic conditions and modifies the expression of inflammatory mediators, angiogenic (VEGF, ANG-1, PDGF and hFGF) and anti-angiogenic (thrombospondin and endostatin, etc.) growth factors, and that of receptors VEGFR and CXCR, in endothelial cells (9).

In this study, we investigated whether CCL extract modifies the expression of angiogenic or inflammatory factors, the rate of the blood flow, and capillary density in an established menopausal model of peripheral vascular disease. The ischemic-/non-ischemic blood perfusion ratio was also evaluated using a non-invasive laser Doppler perfusion imaging system, following which the capillaries were visualized using anti-CD31 immunohistochemistry on endothelial cells in ischemic limb muscles and counted. Additionally, the serum profiles of angiogenic or inflammatory factors were evaluated using an antibody array kit, and the effects of CCL extract on the expression of these factors in the muscles of ischemic limbs were quantified.

\section{Materials and methods}

Preparation of CCL extract. Cuscuta chinensis Lamak (5 kg) was purchased from a local traditional medicine store (Jechoen, Korea) in July of 2017. The authenticity of the plant species was confirmed by one of the authors (Byoung Seob Ko; Korea Institute of Oriental Medicine), after which the seeds were ground into powder. Next, powder $(4 \mathrm{~kg})$ was extracted with $100 \%$ water $(16 \mathrm{~L})$ by heat reflux for $6 \mathrm{~h}$, after which the supernatant was collected and dried using a freeze-dryer for 2 days. The extraction yield was of $0.005 \%$, and $15 \mathrm{~g}$ of CCL-extract was used for subsequent experiments. The plants we used in the experiment were samples produced at GMP facilities in accordance with the Korean Food and Drug Administration's standards for manufacturing and quality control.

Experimental animals and treatments. Female 6-week-old C57BL/6 mice were obtained from Dahan Biolink (Eumseong, South Korea) and divided into five-groups of seven. Mice were allowed to adapt to laboratory conditions (temperature: $20 \pm 2^{\circ} \mathrm{C}$, relative humidity: $45 \pm 5 \%$, light/dark cycle: $12 \mathrm{~h}$ ) for 1 week. All animal experimental procedures were approved by the Ethics Committee of the Korea Institute of Oriental
Medicine (approved no. 17-028). Mice were anesthetized by an animal anesthesia system (Vetequip, Abesko, Gyeonggi, Korea) using 2\% isoflurane (Choongwae Pharma Corp., Seoul, Korea). OVX surgery was assessed according to the criteria of (11), and performed by liagation and excision of ovaries along the upper horns, through aseptic incisions of the dorsal skin and muscle layers. At 7 days after OVX surgery, mice were anesthetized for hind-limb ischemia (HLI) after which the vessels (arteries and veins) of the hind limb were excised on day 0 , and surgery was modified according to the criteria of (12). After a 7 days recover period, 17 $\beta$-estradiol (E2; Sigma-Aldrich; Merck KGaA, Darmstadt, Germany) and CCL extract were prepared in $0.2 \%$ CMC (carboxymethyl cellulose) and administered for every 3-weeks by oral injection (E2 for $100 \mu \mathrm{g} / \mathrm{kg} /$ day and CCL for 150 and $450 \mathrm{mg} / \mathrm{kg} / \mathrm{day}$, respectively). Crude extract doses according to criteria of (13). Mice were euthanized $12 \mathrm{~h}$ after the final injection. And The liver, spleen, peritoneal fat, etc., including tissues from the surgical region, were collected and stored in $4 \%$ formalin or nitrogen immediately for long-term storage at $-80^{\circ} \mathrm{C}$ for the purpose of analysis.

Laser Doppler blood perfusion analysis. The blood flow rates in ischemic/non-ischemic (ISCH/nISCH) hind limbs were measured using a laser Doppler blood perfusion imager (PeriScan-PIM3; Perimed AB, Järfälla, Sweden) under anesthesia (Isoflurane; Choongwae Pharma Corp.) according to the manufacturer's recommendations. The rate of $\mathrm{ISCH} / \mathrm{nISCH}$ blood flow was calculated at -7, 0, 7, 14, and 21 days after HLI by colorimetric assay using PIMSoft (v1.5; Perimed AB).

Immunohistochemical stain. Tissues were fixed in $10 \%$ neutral buffered formalin, embedded in paraffin, and cut into 5- $\mu \mathrm{m}$-thick sections. Endogenous peroxidase and non-specific reactions were blocked with BLOXALL (for $30 \mathrm{~min}$; Vector Lab. Inc., Burlingame, CA, USA) and CAS-BLOCK (for $1 \mathrm{~h}$; Thermo Fisher Scientific, Pittsburgh, PA, USA) at room temperature (RT). Sections were subsequently incubated at RT for $4 \mathrm{~h}$ with an antibody against CD-31 (rabbit polyclonal, 1:250; Abcam). The sections were incubated with Dako REAL ${ }^{\mathrm{TM}}$ Envision $^{\mathrm{TM}} / \mathrm{HRP}$ (Rabbit/Mouse) for $30 \mathrm{~min}$ at RT. Dako REAL ${ }^{\mathrm{TM}}$ DAB+ Chromogen (both from Dako; Agilent Technologies, Inc., Santa Clara, CA, USA) was used as a chromogen, after which the sections were counterstained with Mayer's hematoxylin (Sigma-Aldrich; Merck KGaA) and mounted using Mounting Medium (Thermo Fisher Scientific). Tissue sample was examined under a light microscope (BX43; Olympus, Tokyo, Japan). And all images were captured using an Olympus DP-73 controller and cellSens standard (both from Olympus) under a microscope.

Reverse transcription-quantitative polymerase chain reaction. Total RNA was isolated using an RNeasy Mini Kit (Qiagen, Hilden, Germany), and cDNA was synthesized from $1 \mu \mathrm{g}$ of total RNAs using the Thermo Scientific RevertAid First Strand cDNA Synthesis Kit (Thermo Fisher Scientific, Inc., Waltham, MA, USA) according to the manufacturers' instructions. Briefly, extracted RNA was used as a template for cDNA synthesis using Random Hexamer primers and RevertAid M-MuL V RT, incubated $5 \mathrm{~min}$ at $25^{\circ} \mathrm{C}$ followed by $60 \mathrm{~min}$ at $42^{\circ} \mathrm{C}$. And termination of reaction by heating at 
Table I. The list and sequence of primers used for RT-qPCR analysis.

\begin{tabular}{|c|c|c|c|c|}
\hline No. & Gene & Forward primer ( $5^{\prime}$ to $\left.3^{\prime}\right)$ & Reverse primer ( $5^{\prime}$ to $\left.3^{\prime}\right)$ & $\begin{array}{c}\text { Annealing } \\
\text { temperature }\left({ }^{\circ} \mathrm{C}\right)\end{array}$ \\
\hline 1 & Angiopoietin-1 & ATGCGGTTCAAAACCACACG & AGCAGTTGGATTTCAAGACGG & 58 \\
\hline 2 & Endothelin-1 & AAGGAGTGTGTCTACTTCTGCC & TTCCCTTGGTCTGTGGTCTT & 58 \\
\hline 3 & CXCL12 & GTTTGTCTCTTTGAGCTGAGGC & TGAGACAGAGATGAGCATGGTG & 58 \\
\hline 4 & ICAM-1 & CGGAGCCAATTTCTCATGCTT & ACCCTAGTCGGAAGATCGAA & 58 \\
\hline 5 & IGFBP-3 & GAAACACCACTGAGTCTGAGGA & TGGCCTTTTATGATGACCTCCA & 58 \\
\hline 6 & IL-1b & AGGACCCAAGCACCTTCTTTT & CAGACAGCACGAGGCATTTTT & 59 \\
\hline 7 & IL-6 & AACAGCGATGATGCACTGTCA & TTGCTCTGAATGACTCTGGCT & 59 \\
\hline 8 & TNF- $\alpha$ & GCCAATGGCATGGATCTCAAA & TGGTATGAAATGGCAAATCGGC & 60 \\
\hline 9 & VEGF & AACAAAGCCAGAAAAAAAATCA & TCACCGCCTTGGCTTGTCACA & 58 \\
\hline 10 & VEGFR2 & CTCACACCAGTTTGCAAGAA & AGTACAATGCCTAATCTTCT & 56 \\
\hline 11 & Actin & TACGTCGCCCTGGATTTT & ATGAAAGAGGGCTGGAAGAG & 60 \\
\hline
\end{tabular}

$70^{\circ} \mathrm{C}$ for 5 min. Real-time PCR was performed using SYBR Premix EX Taq (Takara Bio Inc., Otsu, Japan) with 40 cycles for $30 \mathrm{sec}$ at $95^{\circ} \mathrm{C}$, for $30 \mathrm{sec}$ at $60^{\circ} \mathrm{C}$, and for $30 \mathrm{sec}$ at $72^{\circ} \mathrm{C}$ by ABI PRISM 7500HT Sequence Detection System (Applied Biosystems, Foster City, CA, USA). Quantification of target genes was accomplished by the comparative $\mathrm{Ct}$ method, and the levels of mRNAs were normalized by those of $\beta$-actin and presented as relative values. The primers used for real-time PCR were synthesized by Macrogen Inc. (Seoul, Korea) and are presented in Table I.

Analysis of angiogenesis related protein and inflammatory cytokine levels in the serum. The levels of angiogenesis-related proteins and inflammatory cytokines were analyzed using a Mouse Angiogenesis Array Kit and Proteome Profiler Mouse Cytokine Array Kit (R\&D System, Minneapolis, MN, USA) according to the manufacturer's instructions. Briefly, each membrane was incubated with the serum of each group overnight at $4^{\circ} \mathrm{C}$. Bound protein was then detected with streptavidin conjugated to HRP using a digital image system (Chemiluminescence Imaging-Fusion SL, Analis, The Netherlands).

Cell culture and cell viability. Human umbilical vein endothelial cells (HUVECs) were obtained from Lonza (Walkersville, MD, USA) and maintained according to the manufacturer's instructions. Cell viability was detected using an EZ-Cytox kit (DoGenBio Co., Ltd., Seoul, Korea). The HUVEC cells were seeded at a density of $3 \times 10^{4} /$ well in 96 -well plates. High sensitivity water soluble tetrazolium (WST) solution $(10 \mu \mathrm{l}$ per well in a 96-well plate) was added to the culture fluid at 1:1 ratio, while WST solution without cells was used as a blank control. Optical density was determined at various time-points (after $4 \mathrm{~h}$ ) on a microtiter plate reader at $450 \mathrm{~nm}$, after which the percentage viability was calculated using the following formula: Optical density of treated sample/optical density of untreated control x 100 .

Migration assay. HUVECs migration was quantified using a corning Transwell system (Corning, NY, USA). HUVECs were seeded $\left(2 \times 10^{5} /\right.$ well $)$ into the upper chamber $(8 \mathrm{~mm})$ of a Transwell plate in a serum-free medium. In the lower chamber, a complete medium was placed as a chemoattractant. Following incubation at $37^{\circ} \mathrm{C}$ under $5 \% \mathrm{CO}_{2}$ for $6 \mathrm{~h}$, the cells on the top of the polycarbonate membrane were removed using cotton swabs, and the migrating cells on the lower side of the membrane were stained with hematoxylin and eosin $(\mathrm{H} \& \mathrm{E})$ for $5 \mathrm{~min}$. Four random fields were counted under the microscope during each assay.

Tube formation assay. HUVECs $\left(5 \times 10^{4}\right.$ cells/well) were seeded on a Matrigel in 24-well plates supplemented with CCL $(1,10$ and $100 \mu \mathrm{g} / \mathrm{ml})$ and vascular endothelial growth factor (VEGF, $50 \mathrm{ng} / \mathrm{ml}$ ), 17 $\beta$-estradiol (E2, $1 \mathrm{nmol}$ ), and vinblasitne $(1 \mathrm{pmol})$ were added to the media without the addition of growth factors. After $24 \mathrm{~h}$, tubular structures of HUVECs were examined using an inverted microscope (Nikon, Melville, NY, USA), and the total tube length was measured in three fields (4x) using the Image J software version 1.51s (National Institutes of Health, Bethesda, MD, USA).

Statistical analysis. All the results presented are representative of at least 3 independent experiments. The results of the analyses of blood flow, capillary density, and gene expression are presented as the means \pm SD. And the results of the analyses of cell viability, migration, and tube formation are shown as mean \pm SD. Paired Student's t-tests were used to compare each group, while ANOVA with Tukey's test was used for multiple comparison tests using the PRISM software (v6.0; GraphPad, La Jolla, CA, USA). P<0.05 was considered to indicate a statistically significant difference.

\section{Results}

CCL improved blood perfusion. To determine whether CCL (150 or $450 \mathrm{mg} / \mathrm{kg} /$ day) treatment stimulates blood reperfusion in hind-limb ischemia, mice were treated with 17 $\beta$-estradiol (E2) and CCL. As shown in Fig. 1, blood flow in the ischemic hind limbs decreased equally in all surgery groups immediately following ischemic surgery (0 day). 

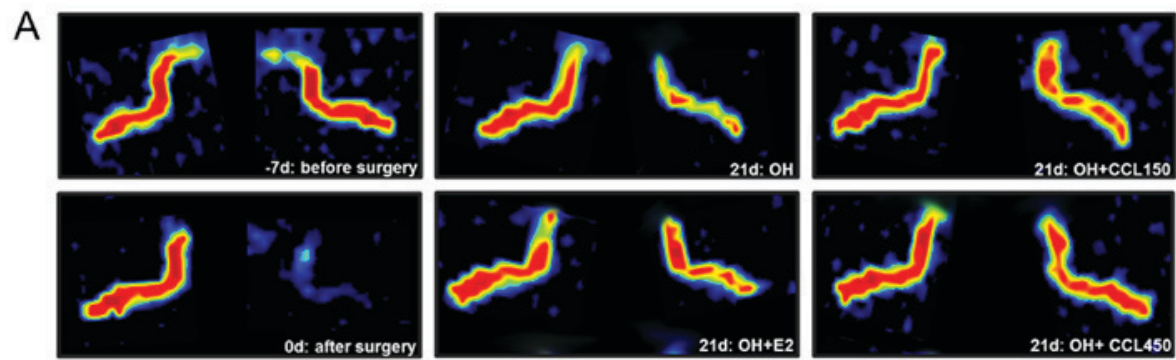

B
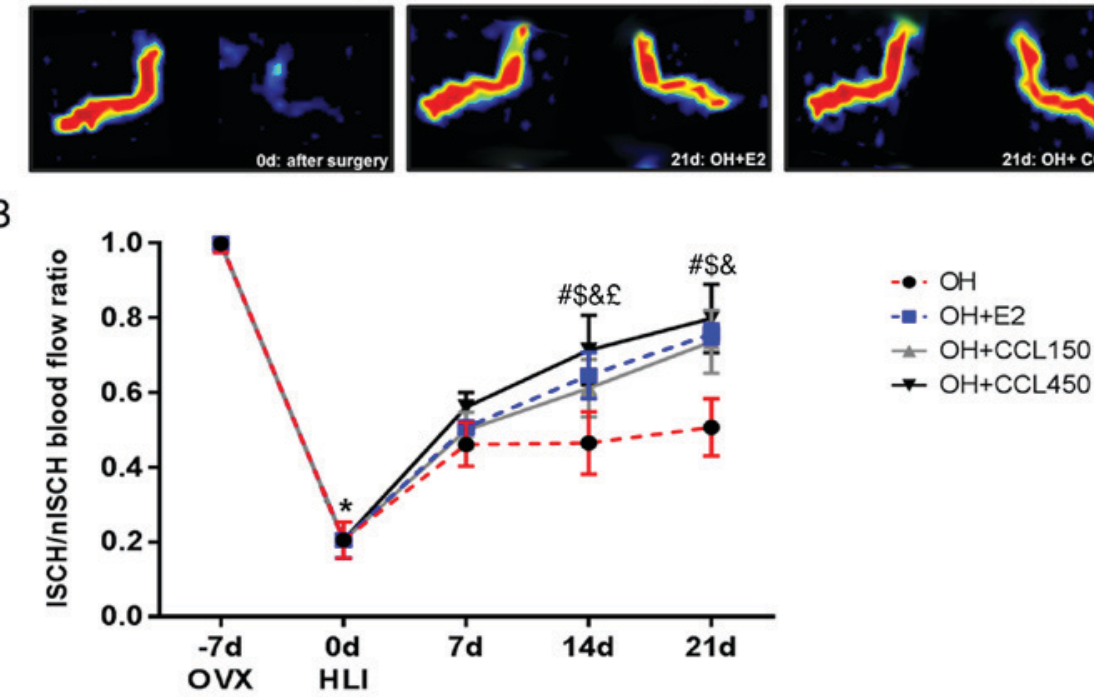

Figure 1. Effect of CCL extract on the blood reperfusion in ischemic hind limb. (A) In color-coded images, low to no flow was displayed as black or deep blue whereas high blood flow was as yellow to red. $\mathrm{ISCH}=$ ishchemia. $\mathrm{nISCH}=\mathrm{Non}$ ischemia. a, OH group; b, OH+E2 group; c, OH+CCL 150 group; d, OH+CCL 450 group. (B) Quantitative evaluation of ischemic/non-ishcemic blood perfusion ratio. ${ }^{*} \mathrm{P}<0.05$ vs. $-7 \mathrm{~d}$; ${ }^{\#} \mathrm{P}<0.05 \mathrm{OH}$ vs. positive control $(\mathrm{OH}+\mathrm{E} 2)$; ${ }^{\$} \mathrm{P}<0.05$ $\mathrm{OH}$ vs. $\mathrm{OH}+\mathrm{CCL} 150 ;{ }^{\&} \mathrm{P}<0.05 \mathrm{OH}$ vs. $\mathrm{OH}+\mathrm{CCL} 450 ;{ }^{\circledR} \mathrm{P}<0.05 \mathrm{OH}+\mathrm{CCL} 150$ vs. OH+CCL450. CCL, Cuscuta chinensis Lamak.

At 14 and 21 days after ischemic surgery, blood perfusion of the ischemic hind limb had improved significantly in all treated groups compared with the vehicle group. In particular, although no significant differences in blood perfusion were detected between the CCL 150 and CCL 450 groups at 21 days after ischemic surgery, a high-dose of CCL (450 mg/kg/day) significantly ameliorated the signs of hind-limb ischemia earlier than a low-dose of CCL (150 mg/kg/day), at 14 days after surgical induction of ischemia.

Capillary density, CD31 immunohistochemical staining. To determine the angiogenic effects of CCL on microcirculation, we evaluated the capillary density in immunostained (anti-CD31) tissue from ischemic thighs and calf muscles. Positive structures were counted on five different microscopic fields per section under 200x magnification to determine capillary density (mean number of capillaries $/ \mathrm{mm}^{2}$ ). Immunohistochemistry showed that the E2-treatment increased capillary density in ischemic muscles compared to the vehicle control. In addition, the capillary density significantly increased in both the low and high-dose CCL-treated groups (Fig. 2).

CCL increased angiogenesis related proteins in serum and $m R N A$ expression in surgical regions. We determined whether CCL treatment promoted the expression of angiogenesis-related factors in serum and wound region tissue of ovariectomized and hind-limb ischemia-induced mice. The results revealed that the serum levels of the endothelin-1 and IGFBP-3 gene expression were significantly different between the treatment and vehicle groups. Moreover, the treatment with CCL increased endothelin-1 protein concentration in a dose-dependent manner (Fig. 3A). Next, we confirmed these findings using RT-PCR. The assessment of endothelin-1 and
IGFBP-3 mRNA levels revealed a significant increase by 1.2- to 1.5-fold (Fig. 3B).

CCL induces wound healing via upregulation of angiogenesis markers in hind-limb ischemic lesions. In parallel with protein array, we confirmed the effects of CCL on the mRNA expression of the angiogenesis-related marker genes VEGF, angiopoetin-1, and VEGFR2 in ischemic lesions of the hind limb. Tissue analyses revealed significant changes in the genes investigated (transcript-level) in response to CCL treatment (Fig. 4). Specifically, the expression of all three genes was upregulated in response to 150 and $450 \mathrm{mg} / \mathrm{ml}$ of CCL, indicating that CCL treatment was effective for wound healing and essential to accelerate angiogenesis.

$C C L$ regulates inflammatory or pro-inflammatory cytokines in serum and mRNA expression in hind-limb ischemic lesions. We conducted the analyses of mouse inflammatory or pro-inflammatory cytokine expression to confirm the differences in the E2- and CCL-treated groups. The treatment with E2 and CCL led to secretion of high levels of CXCL12 (SDF-9) and CD54 (ICAM-1) compared to the vehicle groups (Fig. 5A). Moreover, mRNA expression of CXCL12 and CD54 was upregulated in the E2 and CCL groups (Fig. 5B). The results revealed that mRNA expression of the pro-inflammatory genes, TNF- $\alpha$, IL- 6 and IL-1 $\beta$, was lower than that of the non-treatment group following the treatment with E2 and CCL (Fig. 6).

Evaluation of cell migration and tube formation by CCL in HUVEC. We evaluated the effects of CCL at 0, 1, 5, 10, 50, 100,200 and $300 \mu \mathrm{g} / \mathrm{ml}$ on the viability of HUVECs. As shown in Fig. 7A, no significant cytotoxicity was observed in response to the treatment with $300 \mu \mathrm{g} / \mathrm{ml} \mathrm{CCL}$. Furthermore, the number 

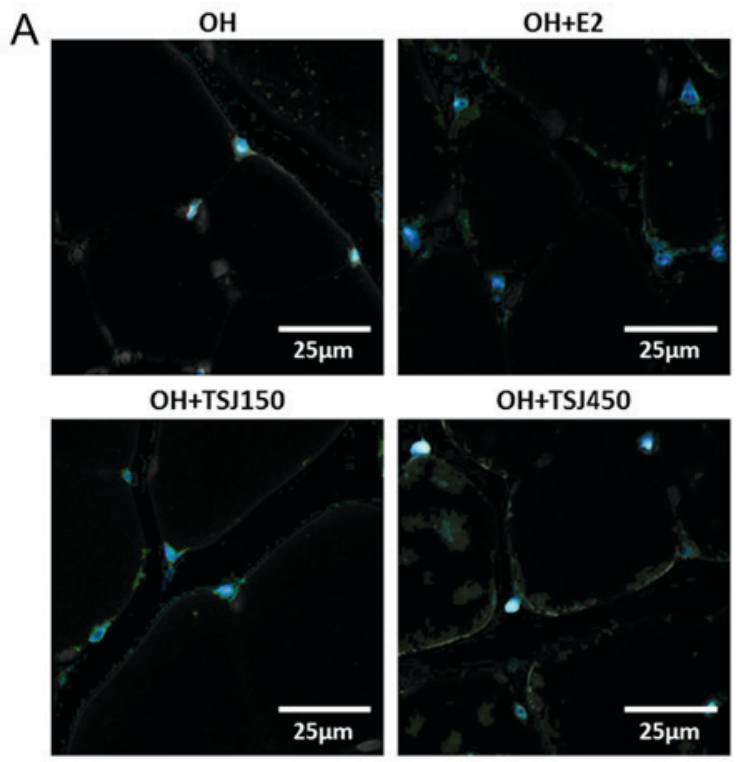

B

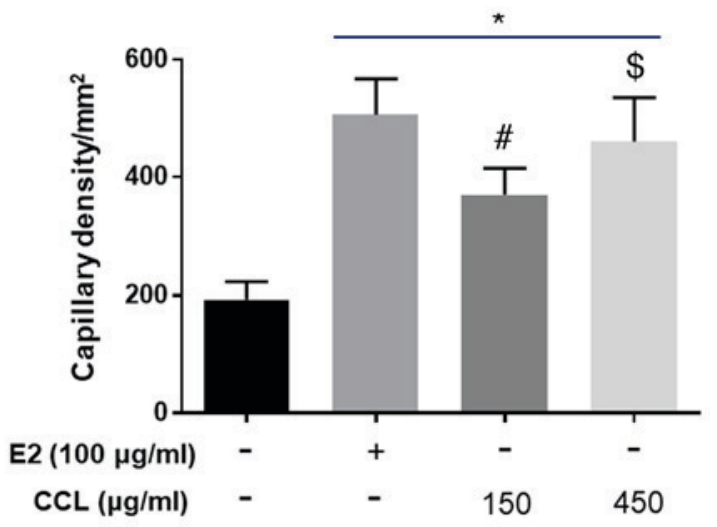

Figure 2.Effect of CCL extract on the capillary density in ischemic hind limb. (A) Representative micro-photographs of the section of ischemic hind-limb muscles stained histochemically for CD-31, (magnification $\mathrm{x} 400$ ). (B) Quantitative analysis of capillary density in ischemic hind-limb muscles. * $<<0.05$ vs. vehicle control $(\mathrm{OH}) ;{ }^{\#} \mathrm{P}<0.05$ vs. positive control $(\mathrm{OH}+\mathrm{E} 2) ;{ }^{\$} \mathrm{P}<0.05$ vs. CCL 150 treatment group. CCL, Cuscuta chinensis Lamak.

A
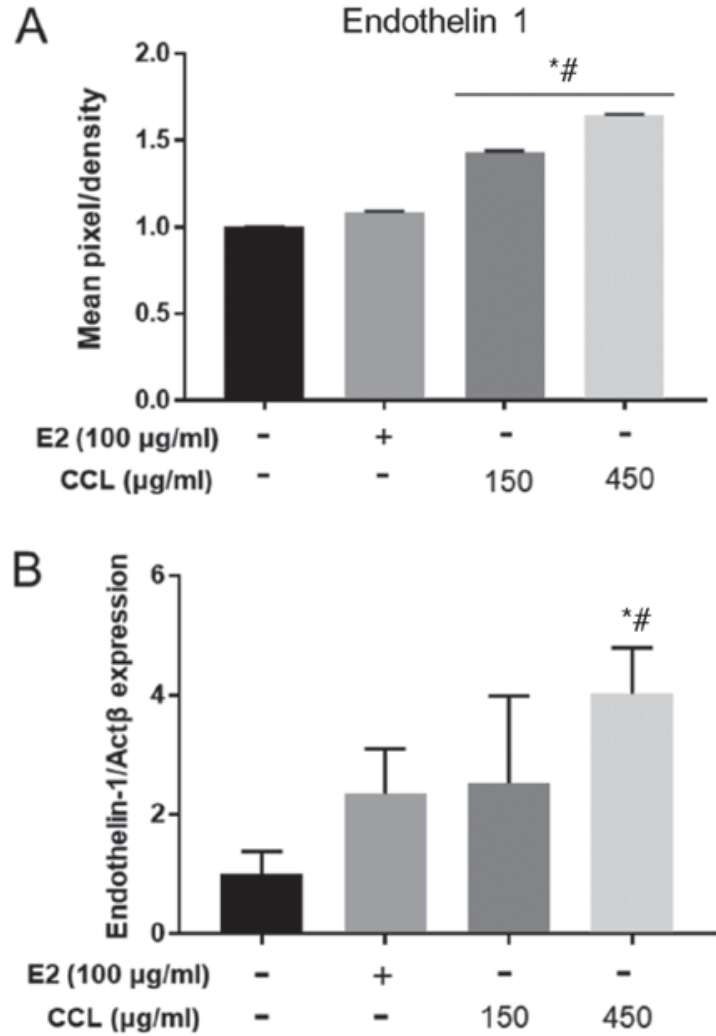
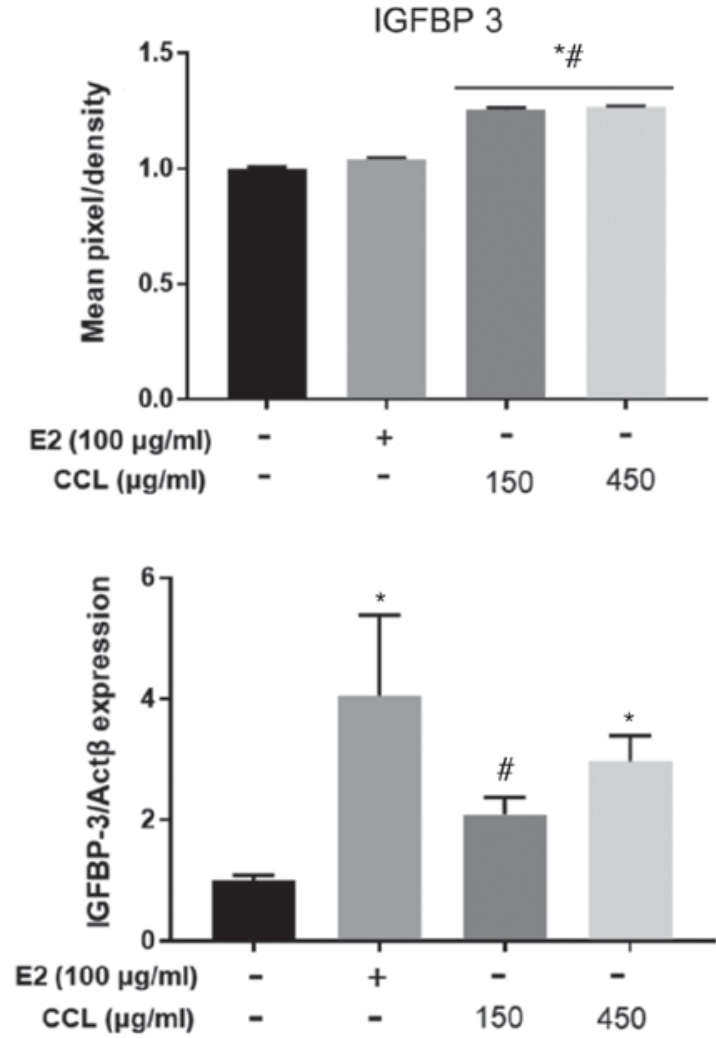

Figure 3. Quantification of angiogenesis related proteins and mRNA expression. CCL regulates the production of angiogenesis related proteins and mRNA in mice serum and surgical region. (A) Using $1 \mathrm{ml}$ pulling serum of each groups and $1.4 \mathrm{ml}$ mixed reconstituted detection antibody cocktail and array buffer. Each groups are untreated or treated with E2 (100 $\mu \mathrm{g} / \mathrm{kg} / \mathrm{day})$ and CCL at different concentration (150, $450 \mathrm{mg} / \mathrm{kg} / \mathrm{day})$ for $21 \mathrm{day}$. Histogram presenting spot intensities indicative of levels of endothelin-1 and IGFBP-3 in mice serum of each groups. ${ }^{*} \mathrm{P}<0.05$ vs. Vehicle; ${ }^{\#} \mathrm{P}<0.05$ vs. E2 treatment group. (B) Comparison of angiogenesis related gene mRNA expression levels between vehicle and treated with $\mathrm{CCL}$ mice surgical hind limb region. ${ }^{*} \mathrm{P}<0.05$ vs. Vehicle; ${ }^{\#} \mathrm{P}<0.05$ vs. E2 treatment group. CCL, Cuscuta chinensis Lamak.

of cells that migrated was significantly increased in VEGF and E2-treated groups, and this increase was also induced in a dose-dependent fashion by CCL treatment compared to the control (Fig. 7B). The tube formation increased in the groups treated with VEGF and E2 compared to the control groups, whereas tube organization was not induced by vinblastine. In CCL-treated groups, the induction of tube formation was observed at the dose of $100 \mu \mathrm{g} / \mathrm{ml}$ (Fig. 7C). 

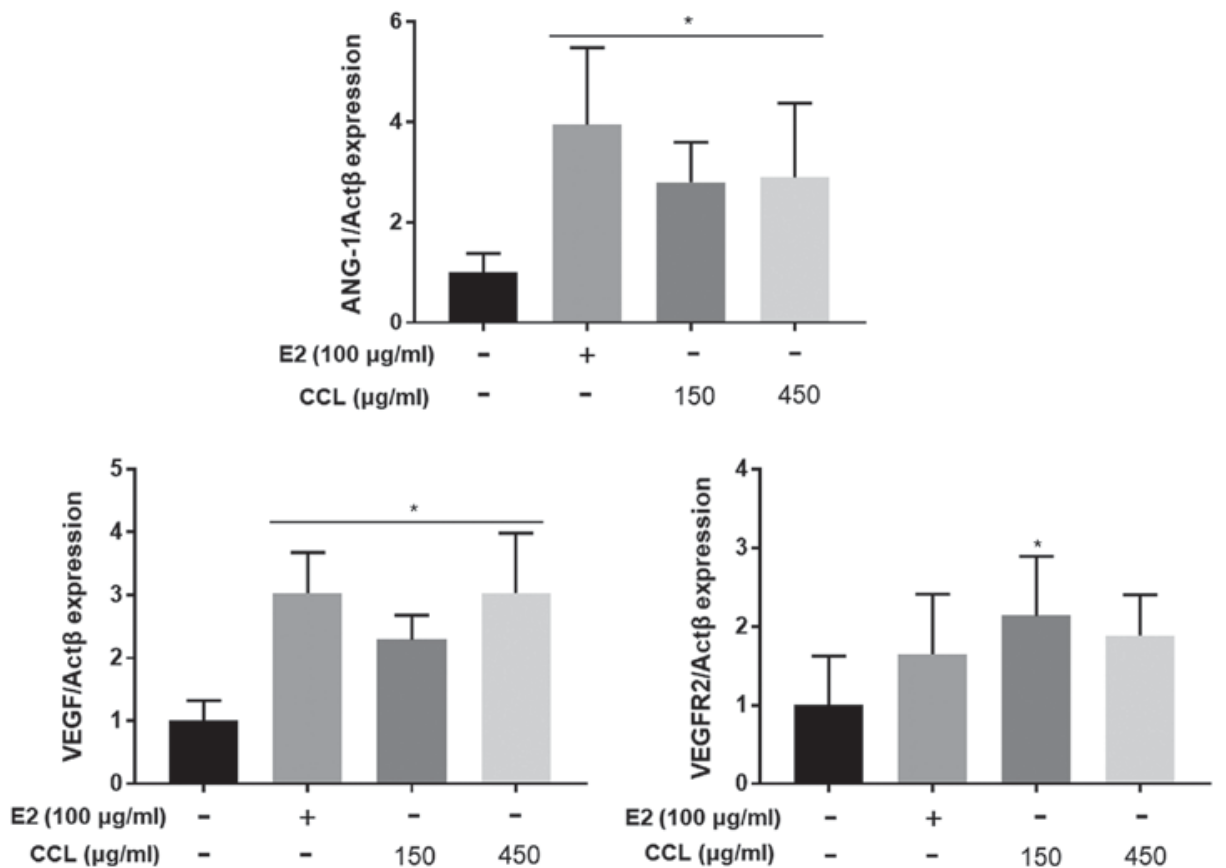

Figure 4. Angiogenesis marker in hind-limb ischemic lesion. Effect of CCL on the mRNA expression level in hind limb surgical region were analyzed by RT-qPCR. Comparison of angiogenesis related genes, Angiopoietin-1, VEGF and VEGFR2, between 4 groups (Vehicle, E2, CCL 150, CCL 450). "P<0.05 vs. Vehicle. RT-qPCR, reverse transcription-quantitative polymerase chain reaction analysis; CCL, Cuscuta chinensis Lamak.

A
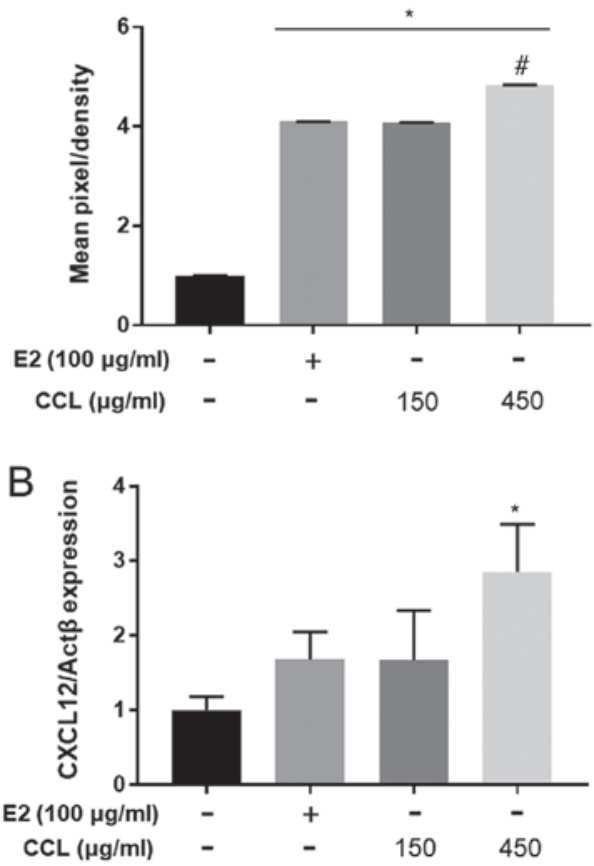

CXCL12 (SDF-1)
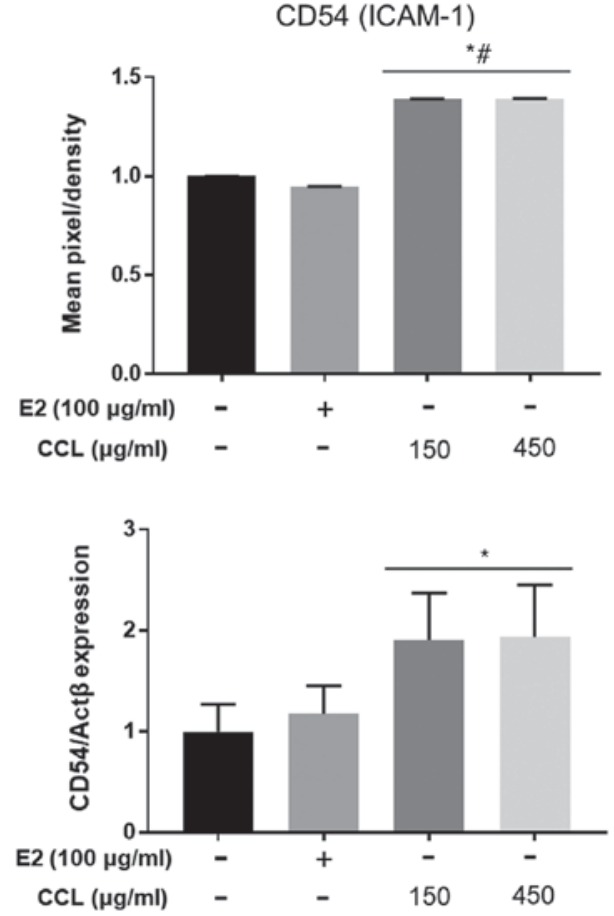

Figure 5. Quantification of inflammation related cytokines and mRNA expression. CCL regulates the production of inflammation related cytokines and mRNA in mice serum and surgical region. (A) Using $1 \mathrm{ml}$ pulling serum of each groups and $1 \mathrm{ml}$ mixed reconstituted detection antibody cocktail and array buffer. Each groups are untreated or treated with E2 $(100 \mu \mathrm{g} / \mathrm{kg} /$ day $)$ and CCL at different concentration $(150,450 \mathrm{mg} / \mathrm{kg} / \mathrm{day})$ for 21 day. Histogram presenting spot intensities indicative of levels of CXCL12 and CD54 in mice serum of each groups. " $\mathrm{P}<0.05$ vs. Vehicle; ${ }^{*} \mathrm{P}<0.05$ vs. E2 treatment group. (B) Comparison of angiogenesis related gene mRNA expression levels between vehicle and treated with CCL mice surgical hind limb region. " $\mathrm{P}<0.05$ vs. Vehicle. CCL, Cuscuta chinensis Lamak.

\section{Discussion}

Peripheral arterial disease is a serious medical condition that develops in response to age and in the groups showing common atherosclerosis risk factors (14). This condition is characterized by a lower limb Doppler signal because of blood vessel blockage associated with critical limb ischemia, intermittent claudication, and rest pain $(14,15)$. The present 

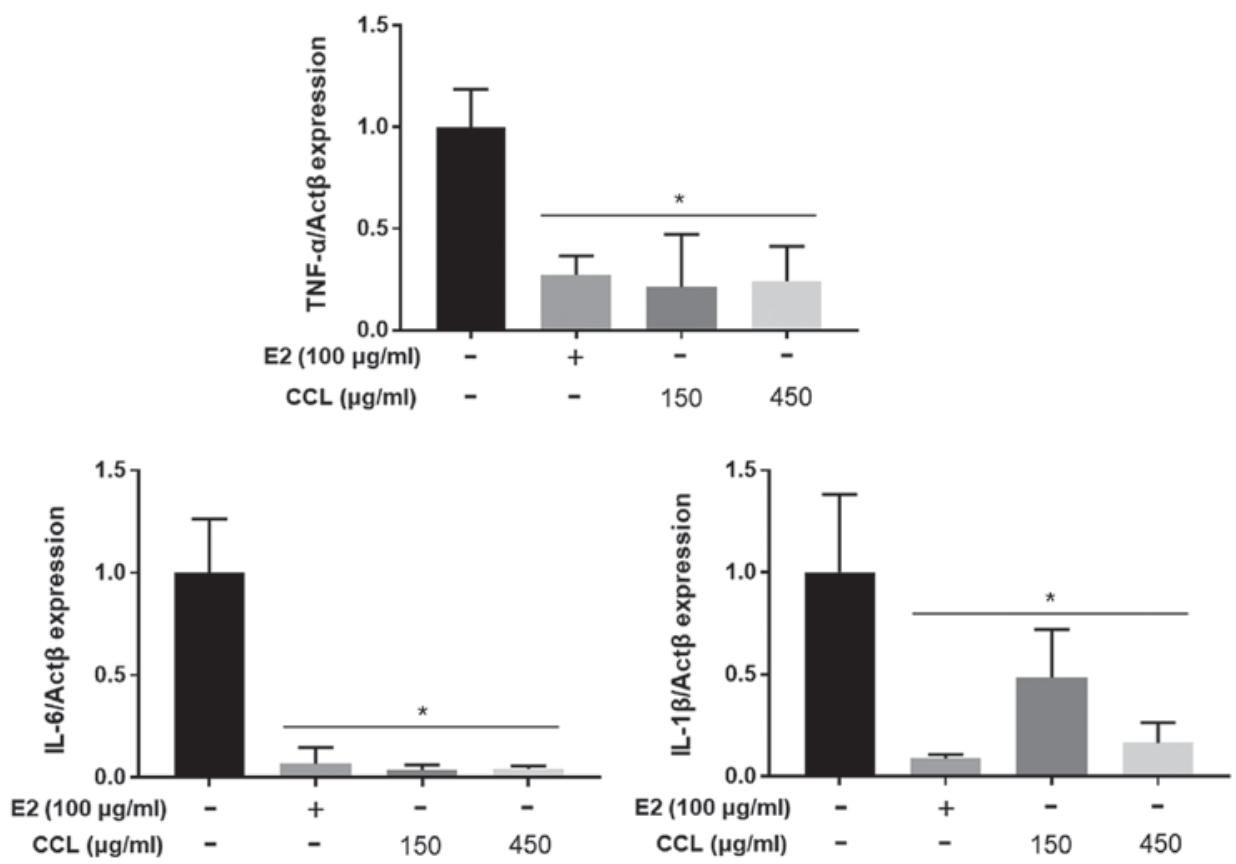

Figure 6. Pro-inflammatory markers in hind-limb ischemic lesion. Effect of CCL on the mRNA expression level in hind limb surgical region were analyzed by RT-qPCR. Comparison of pro-inflammatory related genes, TNF- $\alpha$, IL-6 and IL-1 $\beta$, between 4 groups (Vehicle, E2, CCL 150, CCL 450). "P<0.05 vs. Vehicle. RT-qPCR, reverse transcription-quantitative polymerase chain reaction analysis; CCL, Cuscuta chinensis Lamak.
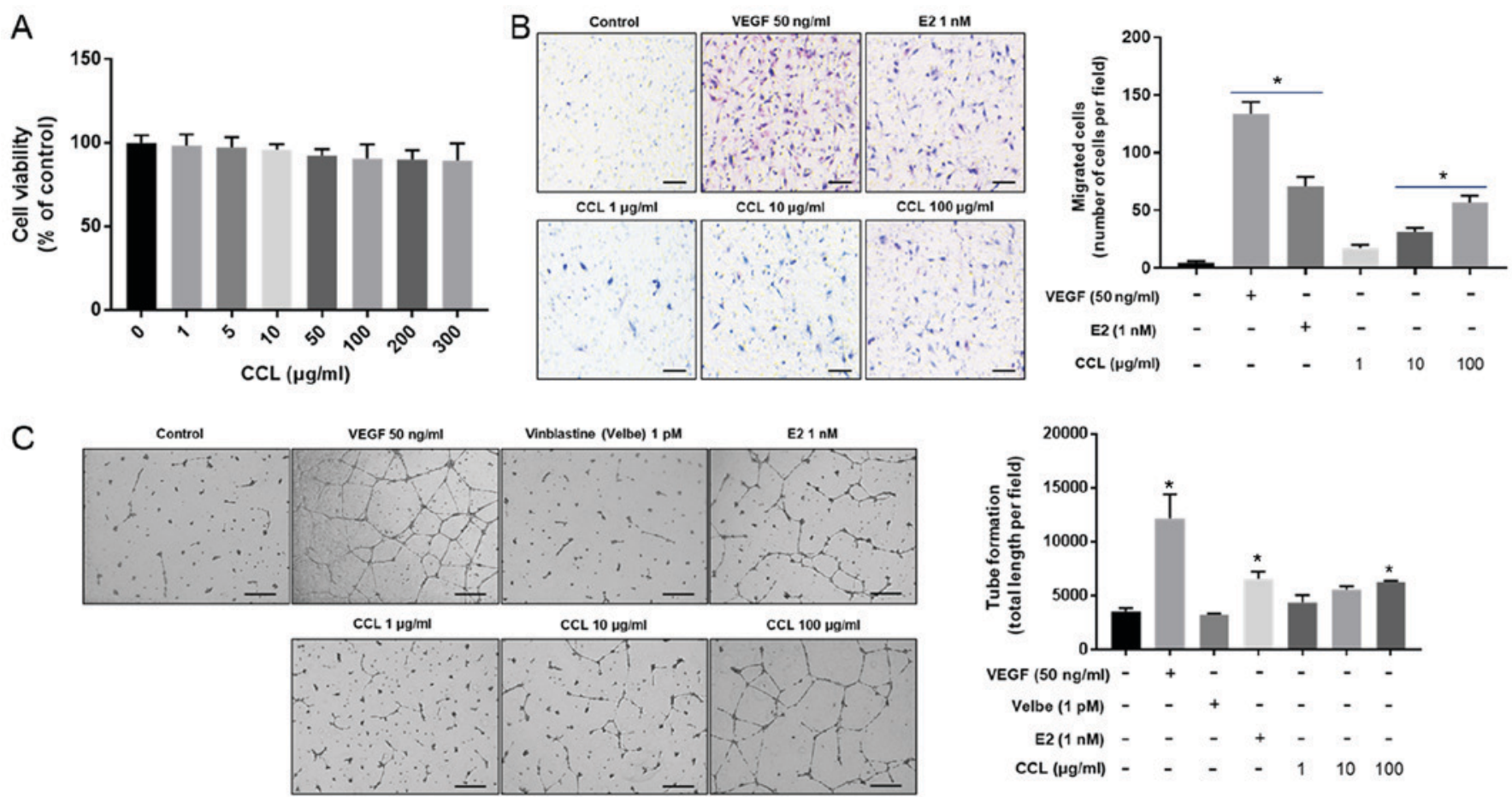

Figure 7. Effects of CCL on HUVEC viability, migration, and tube formation. Cells were treated with indicated concentration of CCL, $50 \mathrm{ng} / \mathrm{ml} \mathrm{VEGF}$ or 1 nmole $17 \beta$-estradiol (E2) or 1 nmole vinblastine (Velbe) on Transwell or Matrigel. (A) Cell viability was analyzed via WST assay. (B) Transwell plate was used to assess migratory activity of photomicrographs (magnification, x200). (C) Cells were observed under the microscope (magnification, x4) and photographed at $12 \mathrm{~h}$ following incubation. Tubes were counted per field in at least three fields after each experiment, and results were expressed as the value of total length. "P $<0.05$ vs. Control (untreated cells). Scale bar $=100 \mu \mathrm{m}$. CCL, Cuscuta chinensis Lamak.

study was conducted to investigate whether CCL extract alleviates the disturbance of the blood flow rate caused by surgical damage in the hind limbs of ovariectomized mice. To accomplish this, we surgically induced estrogen deficiency and hind-limb ischemia in female mice, which was expected to mimic the features of peripheral arterial disease during menopause. We then measured the migration and tube formation of vascular endothelial cells in vitro. In addition, we examined the effects of CCL extract by measuring the changes in the blood flow and capillary density, as well as 
the expression of angiogenic or inflammatory factors in the muscles of the hind limb in vivo.

The wound healing process involves neo-angiogenesis, tissue formation and remodeling, as well as inflammatory response (16-18). In the present study, the migration and tube formation of HUVECs increased significantly following the treatment with 10 and $100 \mu \mathrm{g} / \mathrm{ml} \mathrm{CCL}$. The increased movement of endothelial cells during angiogenesis was previously found to be closely linked to the formation of new blood vessels in wounds $(19,20)$. Ashcroft et al $(21)$ reported accelerated wound healing through a reduction of inflammation, and pro-inflammatory cytokines were shown to play a crucial role during this healing response. In our mouse model, we observed increased blood flow in response to the treatment with CCL extract in the hind limbs of ischemic mice compared to the non-treated group. Overall, these results demonstrated a more pronounced angiogenic response, decreased inflammatory factor expression, and increased capillary density of the limb muscle in response to the treatment with CCL extract. The expression of genes known as angiogenic factors (ANG-1, VEGF and VEGFR) was upregulated by CCL extract treatment in the hind limbs of mice. In contrast, the transcriptional levels of the inflammatory factors TNF- $\alpha$, IL- 6 and IL-1b were reduced. ANG-1 and VEGF are known to induce angiogenic effects and promote the formation of mature neovessels and vascular stabilization in ischemic lesions (22).

In addition, VEGF acts on two receptors, the fms-like tyrosine kinase (flt-1; VEGFR1) and the kinase insert domain-containing receptor, fetal liver kinase (KDR; VEGFR2) (21). It has been previously shown that VEGFR1 is abundantly expressed in both endothelial cells and pericytes, while VEGFR2 is not expressed in pericytes (23). Moreover, VEGFR2 has been shown to play a major role in VEGF-dependent angiogenesis (24). Additionally, IL-6 acts on a variety of organs and cell types and promotes cell growth, and its expression has been reported during wound healing $(15,19,20)$. Furthermore, TNF- $\alpha$ has been implicated as an indirect angiogenic factor, and various cytokines including IL-1b have been shown to be associated with VEGF-dependent angiogenesis $(10,17,18)$.

In the present study, arrays for angiogenic or inflammatory cytokines were conducted to evaluate the expression of angiogenesis-mediated factors ET-1 and IGFBP-3, as well as the inflammation-related factors, CXCL12 and CD54, and their transcriptional expression in ischemic muscles. A previous study has shown that endothelin-1 (ET-1) has important effects on angiogenesis in wounds, and these are mediated by the stimulation of proliferation and collagen production (25). Moreover, IGFBP-3 is known to play an important role in wound healing through a direct binding to fibrinogen (26). As in the case of VEGF, increasing the movement of benign cells in ischemic regions contributes to angiogenesis $(23,24,27)$. A critical role for CXCL12 in SDF1-induced angiogenesis in wounds has been previously documented (28), and recent studies have shown that CXCL12 promotes the synthesis and secretion of VEGF, which contributes to VEGF-induced angiogenesis under ischemic conditions $(29,30)$. Also, an important part of the Fig. 6 is the decrease in IL-1 $\beta$ level compared to the level in a control group. Definitely, a decrease with respect to $\mathrm{E} 2$, used as a positive control, would be a better result; there is a possibility of a difference because the amount of the expression is determined in the hind-limb ischemic lesion, and not in the cell. However, the meaningful result is that all three genes (TNF- $\alpha$, IL-6, IL-1 $\beta$ ) have decreased, dose dependently, and that all have decreased significantly compared to the level in the control group.

Several recent studies have been conducted to mitigate the side effects of chemical drugs and hormone therapy for the symptoms of menopause through treatment with natural substances, and the interest for the use of herbal formulas to treat symptoms in pre/post-menopausal women has increased $(29,31)$. One such formula is CCL, a medicinal herb known to protect the liver and kidneys and potentially useful for treating bone disorders such as rheumatoid arthritis and osteoporosis $(32,33)$. Moreover, prescriptions including CCL are known to reduce the symptoms common to menopausal women, including obesity, metabolic disorders, and colpoxerosis (vaginal dryness), as well as to control the thickness of endothelial cells inside the vaginal wall (34). Also, as shown in Fig. 1, the differences in concentration seem insignificant over time. Therefore, it will not exhibit significant effect of $450 \mathrm{mg} / \mathrm{kg} /$ day and we suggest it will not be possible to expect further improved effects. Furthermore, we always test the effects at low and high concentrations of a crude extract. Natural products are administrated in dose as low as 100 to as high as 500 (35), especially for crude extracts such as CCL. Thus, we selected the lower-range concentration of $150 \mathrm{mg} / \mathrm{kg} /$ day and the higher-range concentration of $450 \mathrm{mg} / \mathrm{kg} / \mathrm{day}$. But, in the case of in vivo study, the concentration is limited and it is necessary to experiment with a wide range of concentrations including low concentrations. There is also a need for higher concentration of experiments to obtain $\mathrm{IC}_{50}$ values for in vitro study.

In conclusion, we demonstrated that CCL improves blood perfusion and peripheral capillary density via regulation of angiogenic and/or inflammatory responses in vivo and in vitro. Based on the current findings, CCL may represent a potent therapeutic agent for the treatment of ischemic injury. Moreover, CCL shows a potential for use as a medicinal herb to improve (post) menopausal women's health.

\section{Acknowledgements}

Not applicable.

\section{Funding}

This study was supported by the Korea Institute of Oriental Medicine (grant no. KNS1515290).

\section{Availability of data and materials}

All data generated or analyzed during the present study are included in this published article.

\section{Author's contributions}

HJK, HY,DHJ, JTH and BSK performed the research, analyzed the data, and wrote the manuscript; HJK and HY performed in vivo experiments and data analysis; DHJ performed in vitro 
experiments and data analysis. All authors read and approved the final manuscript.

\section{Ethics approval and consent to participate}

The present study was approved by the Animal Experiments Ethics Committee of the Korea Institute of Oriental Medicine (17-028, Daejeon, Korea).

\section{Patient consent for publication}

Not applicable.

\section{Competing interests}

The authors declare that they have no competing interests.

\section{References}

1. Moon M, Jeong HU, Choi JG, Jeon SG, Song EJ, Hong SP and Oh MS: Memory-enhancing effects of Cuscuta japonica Choisy via enhancement of adult hippocampal neurogenesis in mice. Behav Brain Res 311: 173-182, 2016.

2. OhH,KangDG,Lee S and LeeHS: Angiotensin converting enzyme inhibitors from Cuscuta japonica Choisy. J Ethnopharmacol 83 105-108, 2002.

3. Jang JY, Kim HN, Kim YR, Choi YH, Kim BW, Shin HK and Choi BT: Aqueous fraction from Cuscuta japonica seed suppresses melanin synthesis through inhibition of the p38 mitogen-activated protein kinase signaling pathway in B16F10 cells. J Ethnopharmacol 141: 338-344, 2012.

4. Patisaul HB and Jefferson W: The pros and cons of phytoestrogens. Front Neuroendocrinol 31: 400-419, 2010.

5. Stefanick ML, Mackey S, Sheehan M, Ellsworth N, Haskell WL and Wood PD: Effects of diet and exercise in men and postmenopausal women with low levels of HDL cholesterol and high levels of LDL cholesterol. N Engl J Med 339: 12-20, 1998.

6. Rubanyi GM, Kauser K and Johns A: Role of estrogen receptors in the vascular system. Vascul Pharmacol 38: 81-88, 2002.

7. Cadenas $\mathrm{C}$ and Bolt HM: Estrogen receptors in human disease. Arch Toxicol 86: 1489-1490, 2012.

8. Fagan SC, Hess DC, Hohnadel EJ, Pollock DM and Ergul A: Targets for vascular protection after acute ischemic stroke. Stroke 35: 2220-2225, 2004.

9. Silvestre JS, Mallat Z, Tedgui A and Lévy BI: Post-ischaemic neovascularization and inflammation. Cardiovasc Res 78: 242-249, 2008

10. Mehrad B, Keane MP and Strieter RM: Chemokines as mediators of angiogenesis. Thromb Haemost 97: 755-762, 2007.

11. Khajuria DK, Razdan R and Mahapatra DR: Description of a new method of ovariectomy in female rats. Rev Bras Reumatol 52 462-470, 2012 (In English, Portuguese).

12. Hamada Y, Gonda K, Takeda M, Sato A, Watanabe M, Yambe T, Satomi $\mathrm{S}$ and Ohuchi N: In vivo imaging of the molecular distribution of the VEGF receptor during angiogenesis in a mouse model of ischemia. Blood 118: e93-e100, 2011.

13. Liao JC, Chang WT, Lee MS, Chiu YJ, Chao WK, Lin YC, Lin MK and Peng WH: Antinociceptive and anti-inflammatory activities of Cuscuta chinensis seeds in mice. Am J Chin Med 42: 223-242, 2014

14. Teodorescu VJ, Vavra AK and Kibbe MR: Peripheral arterial disease in women. J Vasc Surg 57 (Suppl 4): 18S-26S, 2013.

15. Daskalopoulou SS, Daskalopoulos ME, Mikhailidis DP and Liapis CD: Lipid management and peripheral arterial disease. Curr Drug Targets 8: 561-570, 2007.

16. Clement YN, Onakpoya I, Hung SK and Ernst E: Effects of herbal and dietary supplements on cognition in menopause: A systematic review. Maturitas 68: 256-263, 2011.
17. Eming SA, Krieg $\mathrm{T}$ and Davidson JM: Inflammation in wound repair: Molecular and cellular mechanisms. J Invest Dermatol 127: 514-525, 2007.

18. Wong VW and Crawford JD: Vasculogenic cytokines in wound healing. Biomed Res Int 2013: 190486, 2013.

19. Gonzalez AC, Costa TF, Andrade ZA and Medrado AR: Wound healing-A literature review. An Bras Dermatol 91: 614-620, 2016.

20. Hwang SH, Lee BH, Choi SH, Kim HJ, Won KJ, Lee HM, Rhim H, Kim HC and Nah SY: Effects of gintonin on the proliferation, migration, and tube formation of human umbilical-vein endothelial cells: Involvement of lysophosphatidic-acid receptors and vascular-endothelial-growth-factor signaling. J Ginseng Res 40: 325-333, 2016.

21. Ashcroft GS, Greenwell-Wild T, Horan MA, Wahl SM and Ferguson MW: Topical estrogen accelerates cutaneous wound healing in aged humans associated with an altered inflammatory response. Am J Pathol 155: 1137-1146, 1999.

22. Zacharek A, Chen J, Cui X, Li A, Li Y, Roberts C, Feng Y, Gao Q and Chopp M: Angiopoietin1/Tie2 and VEGF/Flk1 induced by MSC treatment amplifies angiogenesis and vascular stabilization after stroke. J Cereb Blood Flow Metab 27: 1684-1691, 2007.

23. Shao R, Yan W and Rockey DC: Regulation of endothelin-1 synthesis by endothelin-converting enzyme-1 during wound healing. J Biol Chem 274: 3228-3234, 1999.

24. Campbell PG, Durham SK, Hayes JD, Suwanichkul A and Powell DR: Insulin-like growth factor-binding protein-3 binds fibrinogen and fibrin. J Biol Chem 274: 30215-30221, 1999.

25. Abbott JD, Huang Y, Liu D, Hickey R, Krause DS and Giordano FJ: Stromal cell-derived factor-1alpha plays a critical role in stem cell recruitment to the heart after myocardial infarction but is not sufficient to induce homing in the absence of injury. Circulation 110: 3300-3305, 2004.

26. Ruiz de Almodovar C, Luttun A and Carmeliet P: An SDF-1 trap for myeloid cells stimulates angiogenesis. Cell 124: 18-21, 2006.

27. Jin DK, Shido K, Kopp HG, Petit I, Shmelkov SV, Young LM, Hooper AT, Amano H, Avecilla ST, Heissig B, et al: Cytokine-mediated deployment of SDF-1 induces revascularization through recruitment of $\mathrm{CXCR}^{+}$hemangiocytes. Nat Med 12: 557-567, 2006.

28. Restivo TE, Mace KA, Harken AH and Young DM: Application of the chemokine CXCL12 expression plasmid restores wound healing to near normal in a diabetic mouse model. J Trauma 69: 392-398, 2010.

29. Hidaka T, Yonezawa R and Saito S: Kami-shoyo-san, Kampo (Japanese traditional medicine), is effective for climacteric syndrome, especially in hormone-replacement-therapy-resistant patients who strongly complain of psychological symptoms. J Obstet Gynaecol Res 39: 223-228, 2013.

30. Kijowski J,Baj-Krzyworzeka M, Majka M, Reca R, Marquez LA, Christofidou-Solomidou M, Janowska-Wieczorek A and Ratajczak MZ: The SDF-1-CXCR4 axis stimulates VEGF secretion and activates integrins but does not affect proliferation and survival in lymphohematopoietic cells. Stem Cells 19: 453-466, 2001.

31. Yin QZ, Lu H, Li LM, Yie SM, Hu X, Liu ZB, Zheng X, Cao S and Yao ZY: Impacts of You Gui Wan on the expression of estrogen receptors and angiogenic factors in OVXrat vagina: A possible mechanism for the trophic effect of the formula on OVX-induced vaginal atrophy. Mol Med Rep 8: 1329-1336, 2013.

32. May MJ, D'Acquisto F, Madge LA, Glockner J, Pober JS and Ghosh S: Selective inhibition of NF-kappaB activation by a peptide that blocks the interaction of NEMO with the IkappaB kinase complex. Science 289: 1550-1554, 2000.

33. Yang HM, Shin HK, Kang YH and Kim JK: Cuscuta chinensis extract promotes osteoblast differentiation and mineralization in human osteoblast-like MG-63 cells. J Med Food 12: 85-92, 2009.

34. Akimova E, Lanzenberger R and Kasper S: The serotonin-1A receptor in anxiety disorders. Biol Psychiatry 66: 627-635, 2009.

35. Pyun BJ, Yang H, Sohn E, Yu SY, Lee D, Jung DH, Ko BS and Lee HW: Tetragonia tetragonioides (Pall.) Kuntze regulates androgen production in a Letrozole-induced polycystic ovary syndrome model. Molecules 23: E1173, 2018. 